\title{
Especialização e diversificação produtiva: um modelo de painel espacial para a indústria extrativa mineral em Minas Gerais, 2000-2010
}

Specialization and productive diversification: a space panel model for the mineral extraction industry in Minas Gerais, 2000-2010

\author{
Mariana Medeiros Nahas (1) \\ Rodrigo Ferreira Simões (2) \\ André Braz Golgher (3) \\ Luiz Carlos de Santana Ribeiro (4)
}

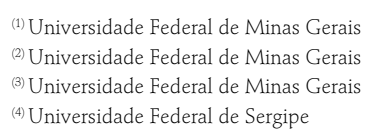

(4) Universidade Federal de Sergipe

\begin{abstract}
The Mining Industry is important for Minas Gerais. In the 2000s, it doubled its share of state added value, contributing $6.9 \%$ of GDP and $20 \%$ of industrial GDP in 2010 . However, its local effects on regional development are ambiguous and poorly studied. This article aims to analyze the net effects of mining on the complexification of the municipal productive structure of the largest miners in the state. We used a set of regional and urban economics indicators as well as spatial panel modeling. Empirical evidence indicates that during the 2000s there was a relative loss of the regional specialization and concentration concentration differentials in the sectors of High and Medium Technological Intensity, Traditional Productive Services and Modern Productive Services.
\end{abstract}

\section{Keywords}

Mining Industry; Spatial Panel Data Model, Productive Diversification; Minas Gerais; Regional Development.

JEL Codes R580; R320; Q20.

\section{Resumo}

A indústria extrativa é importante para Minas Gerais. Nos anos 2000, ela dobrou sua participação no valor adicionado estadual, contribuindo com $6,9 \%$ do Produto Interno Bruto (PIB) e 20\% do PIB industrial, em 2010. No entanto, seus efeitos locais sobre o desenvolvimento regional são ambíguos e pouco estudados. Este artigo busca analisar os efeitos líquidos da mineração sobre a complexificação da estrutura produtiva municipal dos maiores mineradores do estado. Foi utilizado um conjunto de indicadores de economia regional e urbana, bem como a modelagem de painel espacial. As evidências empíricas indicam que, durante a década de 2000, houve perda relativa dos diferenciais regionais de especialização e concentração produtiva nos setores Indústria de Alta e Média Intensidade Tecnológica, Serviços Produtivos Tradicionais e Serviços Produtivos Modernos.

\section{Palavras-chave}

indústria extrativa mineral; painel espacial, diversificação produtiva; Minas Gerais; Desenvolvimento Regional.

Códigos JEL R580; R320; Q20. 


\section{Introdução}

A mineração é essencial para a vida das pessoas, embora os efeitos da atividade mineral sobre a dinâmica produtiva local sejam ambíguos em decorrência de peculiaridades que a permeiam. A formação de jazidas minerais depende de características intrínsecas ao subsolo e, portanto, são espacialmente concentradas. Essa rigidez locacional confere características próprias aos empreendimentos minerais bem como aos territórios que os abrigam, podendo gerar expressivos influxos migratório e de riqueza em curto espaço de tempo, além de impactos sobre a cultura local e o meio ambiente. Um exemplo recente foi o rompimento das barragens de rejeitos do Fundão e do Feijão, nos municípios de Mariana ${ }^{1}$ e Brumadinho, Minas Gerais.

Do ponto de vista econômico, pode-se configurar um enclave produtivo, pois é intensiva em capital fixo, pouco conectado e reaproveitável por outras indústrias, e poupadora de mão de obra. Determinada região especializada na mineração tende a se tornar dependente da mineração e se não houver algum mecanismo de incentivo à sua diversificação o risco de lock-in ${ }^{2}$ é considerável. Assim, ainda hoje, há um vasto debate a respeito dos efeitos líquidos da mineração sobre o desenvolvimento dos territórios minerários (Viana, 2012; Enriquez, 2008; Radetzky, 1992; Davis, 1995, 1998; Davis; Tilton, 2002; Ferranti et al., 2002; Pegg, 2006; Lewiz, 1954; Shafer, 1994; Freubenburg; Gramiling, 1998; Gylfason, 2000; Whitemore, 2006).

Numa perspectiva contemporânea, evidências empíricas indicam expressiva capacidade de geração de riqueza dessa atividade e que economias de base mineral experimentaram baixas taxas de inovação e empreendedorismo, indicadores socioeconômicos inferiores, má distribuição de renda, pouca diversificação econômica, exportações concentradas em produtos primários e mercado de trabalho monopsônico (Auty, 1990; Sachs; Warner, 1995; 2001;2006; Rosser, 2006; Oliveira, 2010).

A qualidade das instituições, complementarmente, parece ser determinante para propiciar que a janela de oportunidades da mineração seja suficiente para transpor tais desafios (Enriquez, 2008; Furtado; Urias, 2013). A existência de um ambiente econômico e institucional que possibilite à

1 Para maiores informações, ver Simonato (2016).

2 Efeito lock-in: rigidez da estrutura produtiva e tecnológica e das relações econômicas (Arthur, 1983). 
atividade gerar outros benefícios além das receitas tributárias, taxas e royalties é elemento fundamental para a intensificação do desenvolvimento econômico. Governos fortes, associados à acumulação de conhecimento e expertise na prática mineradora, podem ser capazes de garantir que o país escape da maldição dos recursos naturais (Auty; Warhurst, 1993; Warhurst, 1999; Hilson, 2000; Veiga et al., 2001, Davis; Tilton, 2005).

O Brasil se enquadra no terceiro perfil, no qual a mineração proporciona ganhos para o país como um todo. Entre os anos 2004 e 2010, as exportações de bens minerais e os Investimentos Estrangeiros Diretos (IED) contribuíram para a consolidação de resultados positivos no setor externo. Especificamente em Minas Gerais, a mineração foi uma importante força motriz que impulsionou seu desenvolvimento econômico, regional e urbano. Atualmente, esse estado possui o terceiro maior PIB do país, sendo a mineração o principal pilar de sua economia. Devido ao rápido crescimento da demanda mundial, a vocação mineral tornou-se novamente evidente. Entre os anos 2000 e 2010, impulsionada pela demanda externa, essa indústria apresentou taxa de variação média do valor adicionado de 8,6\% a.a. e, entre os dois últimos anos desse período, foi a atividade econômica de maior dinamismo, com crescimento de $29 \%$, muito acima da média estadual. Mais que isso, em 2010, o minério de ferro, principal produto da pauta exportadora mineira, obteve crescimento de $101 \%$. O saldo da balança comercial mineral do estado foi superior a US\$ 15 bilhões.

No entanto, na esfera local, os efeitos líquidos da extração mineral são difusos. Essa unidade de análise absorve todos os custos socioambientais decorrentes da extração, além de estar sujeita à incerteza acerca do desempenho futuro do empreendimento em si, apropriando-se de apenas uma parcela dos benefícios gerados.

O objetivo principal deste artigo é analisar o efeito do superciclo da mineração sobre a diversificação da economia municipal, em termos de complexificação da estrutura produtiva dos municípios mineradores de Minas Gerais, no período de 2000 a 2010. Entende-se que esta seria a peça fundamental para o desenvolvimento de economias com base na mineração, pois, a superação da tendência ao enclave produtivo mineral significa a redução da dependência externa e das rendas advindas dessa atividade. Em outros termos, a complexificação da estrutura produtiva indica que a riqueza natural, exaurível, proveniente desses subsolos foi utilizada de forma a proporcionar o bem-estar dos atores residentes atuais e futuros, 
ou seja, a concretização do processo de desenvolvimento sustentável dos territórios minerários, pelo menos em termos econômicos. ${ }^{3}$

Este artigo está dividido em mais quatro seções. A primeira aborda aspectos conceituais. A segunda seção apresenta a metodologia utilizada. $\mathrm{Na}$ terceira são discutidos os resultados. A última seção é reservada para as considerações finais.

\subsection{Concentração e diversificação: aspectos conceituais}

A análise da contribuição dos recursos naturais para o desenvolvimento regional e urbano não é tema recente. North (1955) e Hirschman (1958) analisam, sob óticas diferentes, a capacidade de uma base produtiva primária promover o crescimento local. Para North (1955), uma base exportadora saudável e em pleno funcionamento é capaz de proporcionar até mesmo a diversificação em relação a si própria, conforme o ocorrido em algumas regiões dos Estados Unidos no século XIX. Hirschman (1976) aponta o baixo poder de encadeamento da atividade primária exportadora como gargalo ao desenvolvimento e classifica a atividade como enclave, ou seja, possuidora de restritos elos produtivos para trás com o restante da economia, intensiva em capital e não intensiva em trabalho. Contudo, Hirschman (1958) salienta que a magnitude das rendas provenientes pode gerar novos investimentos voltados para o mercado interno, contribuindo para o aprofundamento do desenvolvimento local, através dos efeitos spillovers sobre o investimento induzido, renda, emprego e produção.

As relações estabelecidas entre firma-indústria-entorno são complexas e proporcionam amplas possibilidades e oportunidades. Dessa forma, é preciso considerar o papel das economias externas dinâmicas. As externalidades MAR são provenientes da concentração geográfica e da especialização das firmas localmente aglomeradas (modelo Marshall - Arrow - Romer). Seu mecanismo de funcionamento pode ser resumido por meio da Tríade Marshalliana: efeitos de encadeamento intersetorial, gerando economias pecuniárias; transbordamentos de conhecimento (Griliches, 1992) entre as firmas concentradas espacialmente; formação de polos especializados de

3 A diversificação produtiva que gera outras possibilidades econômicas para as localidades minerárias não garante que os malefícios socioambientais advindos da mineração sejam também mitigados. 
mercado de trabalho e suas interações, incluindo a retroalimentação do sistema (Marshall, 1890).

Como municípios ricos em bens minerais são geralmente vizinhos uns dos outros, a indústria extrativa mineral em Minas Gerais é espacialmente aglomerada e especializada. Algumas características da interação empresa mineradora/entorno são pressupostos para que a Tríade Marshalliana. A demanda não cria automaticamente a oferta e o preenchimento das necessidades de insumos demandados depende da distância entre a tecnologia superior e a inferior (Iglesias, 2010). Os territórios com baixo desenvolvimento tecnológico não possuem as condições necessárias para interiorizar possíveis transbordamentos de conhecimento. Mais que isso, a extensão da transferência tecnológica depende não só da capacidade de aprendizado das firmas locais, mas também dos esforços intencionais da economia local para absorver esses conhecimentos (Kokko, 1994; Rodriguéz-Claire, 1996).

Por sua vez, Jacobs (1969) descreve sobre as externalidades oriundas da diversificação produtiva. A fecundação cruzada de ideias entre os vários setores de atividade, concentrados nas cidades, leva continuamente à adição de novos trabalhos aos velhos e ao processo de inovação produtiva. Apesar de reconhecer os ganhos de eficiência advindos da especialização, que repetir e expandir (mesmo que de maneira eficiente) aquilo que já foi feito é diferente de inovar sistematicamente na produção de bens e serviços. Assim, a sustentabilidade do desenvolvimento econômico local se dá de acordo com a adição de novos trabalhos aos velhos, possível apenas em uma cidade - centro urbano diversificado - que é o local privilegiado das relações econômicas.

A ocorrência conjunta de externalidades MAR e de diversificação é possível, dado que seus arcabouços teóricos não são mutuamente excludentes. A divergência entre eles se dá principalmente sobre qual fonte de externalidade é a fonte primaz do crescimento. Contudo, ambos apontam a interação dos agentes e a consequente geração de transbordamentos de conhecimento como o maior motor do crescimento (Glaeser et al., 1992).

No caso de Minas Gerais, a mineração foi uma importante força motriz de criação das cidades, ${ }^{4}$ as quais são responsáveis primordiais pelo desenvolvimento econômico e pela diversificação produtiva (Jacobs, 1969).

4 Vide a formação histórica de Ouro Preto, Diamantina, Congonhas e Mariana. 
Sendo assim, a relação entre a coexistência de alta intensidade mineral e ambiente produtivo inovador e dinâmico, potencial gerador de transbordamentos de conhecimento, será tomada como evidência empírica de externalidades de diversificação.

\section{Metodologia}

No período analisado, foram utilizados os municípios do maior estado mineral brasileiro. ${ }^{5}$ No ano de 2010, 352 municípios de Minas Gerais possuíam algum tipo de extração mineral em seu território. Esse número impossibilita um estudo caso a caso. Dessa forma, a análise empírica foca nos 22 maiores municípios ${ }^{6}$ mineradores do estado, os quais foram selecionados a partir do Valor da Produção Mineral municipal (VPM), no ano de $2010^{7}$. A Figura 1 mostra as mesorregiões de Minas Gerais e os 22 maiores mineradores, que compõem o grupo Fortemente Minerador. Em função do significativo desempenho econômico da atividade e da resultante geração de renda mineral, os municípios contidos no grupo Fortemente Mineradores, que gozam de alta intensidade mineral, possuíram volume suficiente de renda para promover investimentos locais para o desenvolvimento da capacidade produtiva municipal, durante a década de 2000 .

Além da receita de tributos como Imposto Territorial Rural (ITR) ou Imposto sobre a Propriedade Territorial Urbana (IPTU), que estão relacionados no nível de atividade econômica local, há ainda o repasse da cota-parte do Imposto sobre Circulação de Mercadorias e Serviços (ICMS) ${ }^{8}$ e cota-parte do Imposto de Renda (IR). Outra importante fonte de recursos é a cota-parte da Compensação Financeira pela Exploração Mineral (CFEM),

\section{Excluindo-se petróleo e gás natural.}

6 Ver Anexo 1.

7 Municípios com Valor da Produção Mineral (VPM) superior à média dos 352 municípios foram incluídos no grupo Fortemente Minerador. A utilização da média aritmética enquanto parâmetro de seleção do número de municípios do grupo Fortemente Minerador deve-se ao alto grau de concentração espacial do VPM em Minas Gerais. Esses 22 municípios correspondem a $94 \%$ do VPM e a apenas $6 \%$ do total de localidades que abrigam algum tipo de extração mineral.

8 Apesar da desoneração do ICMS para as commodities minerais exportadas, o Valor Adicionado Fiscal (VAF) da atividade Extrativa Mineral é contabilizado no montante municipal. Assim, o VAF das commodities minerais contribui para a mensuração da cota-parte do ICMS recebido pelo município minerador. 
que equivale a aproximadamente a $2,2 \%$ do valor da produção do minério de ferro. Porém, é permitida à empresa mineral realizar deduções sobre o montante devido. Desse valor, $65 \%$ é remetido ao município?.

Figura 1 Inserção dos maiores municípios mineradores no espaço de Minas Gerais para 2010

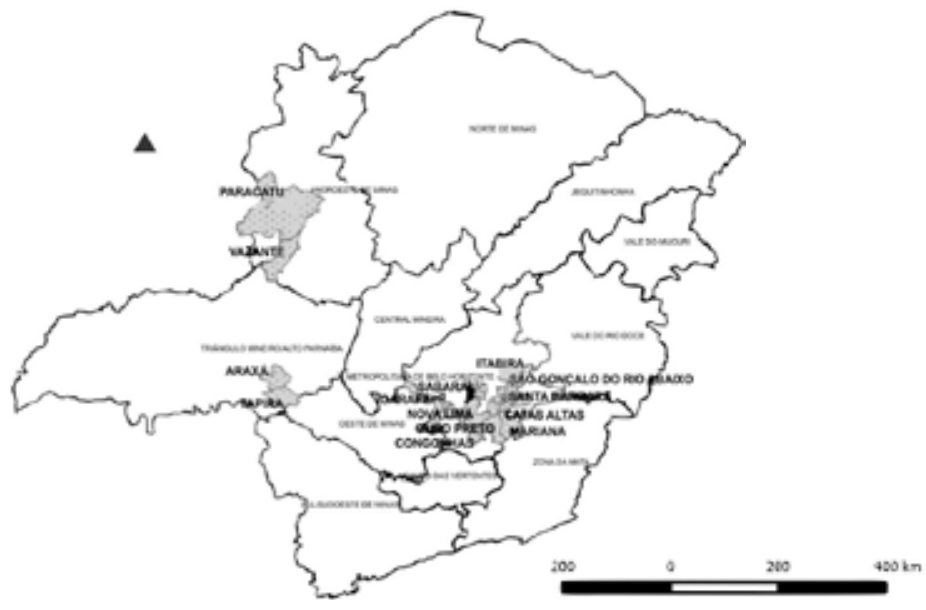

Fonte: Elaboração própria a partir da Divisão Territorial Brasileira, IBGE, 2007.

Foi utilizada fundamentalmente a base de dados dos Censos Demográficos 2000 e 2010, elaborados pelo Instituto Brasileiro de Geografia e Estatística (IBGE). A utilização de uma base única para informações produtivas e não produtivas confere consistência aos resultados empíricos. Ressalta-se que o índice de Desenvolvimento Humano (IDH) (Atlas do Desenvolvimento Humano) e Gastos Públicos Municipais (FINBRA) e arrecadação de CFEM municipal (DNPM) foram coletados em outras bases de dados.

\subsection{Modelo empírico}

A modelagem empírica é apresentada nesta seção. Trata-se do modelo base, com caráter ilustrativo, que possibilita entender como cada um des-

9 No caso de Nova Lima, por exemplo, a receita oriunda apenas da cota-parte da CFEM foi de aproximadamente R $\$ 53$ milhões em 2010. Esse valor respondeu por 19\% das receitas orçamentárias municipais para o mesmo ano. 
ses aspectos se relacionam com a análise proposta. $\bigcirc$ desenvolvimento do modelo empírico, incluindo a abordagem de dados em painel e aspectos espaciais, será apresentado na subseção 2.2 , que antecede a apresentação dos resultados.

Figura 2 llustração do modelo base desenvolvido para capturar os efeitos da indústria extrativa mineral sobre a complexificação da estrutura produtiva municipal - Minas Gerais, 2000 e 2010

\section{Complexificação Produtiva}

medida pelos diferenciais regionais (knowledge spillovers, spillovers tecnológicos) nos setores Indústria de Alta e Média Intensidade Tecnológicas (HATZICHRONOGLOU, 1997), os Serviços Produtivos Tradicionais e Serviços Produtivos Modernos (LIMA et al., 2012), por meio de componentes principais.

$$
\overbrace{D H_{i t}+A R_{i t}+I M_{i t}}^{c_{g} C P_{i t}}=X_{i t} \beta+\varepsilon_{i t}
$$

Desenvolvimento Humano (DH) + Intensidade Mineral (IM) + Atributos Regionais (AR)

$D_{\text {it }}$
Desigualdade Humano Amplo
DRH $_{\text {it }}$

Desigualdade e Renda

$A N R_{i t}$

Grau de Instrução e Riqueza
$F T M_{\text {it }}$ dummy,

indica alta intensidade mineral

$F T M d_{\text {it }}$ FTM x Distância à BH
$I N V_{i t}$ Investimentos públicos municipais $p c$

$T E L_{i t}$ Tamanho da Economia Local (densidade do emprego local)

Fonte: Elaboração própria.

Na Figura 2 são descritas as variáveis: $c_{g} C P_{i}=$ é a variável resposta, representada por meio do componente principal $g$ da dimensão Complexificação Produtiva do município $i$;

- $D H_{i}$ : variáveis explicativas de controle associadas ao desenvolvimento humano do município $i$;

- $A R_{i}$ : variáveis explicativas de controle associadas aos atributos regionais do município $i$;

- $I M_{i}$ : variáveis de interesse relacionadas à intensidade mineral do município $i$;

A seguir, cada um dos quatro termos do modelo acima é detalhado. 


\section{A dimensão Complexificação Produtiva}

A dimensão Complexificação Produtiva, incorporada no termo $c_{g} C P_{i}$, relaciona-se com a estrutura produtiva e o dinamismo da economia local, pois resume os diferenciais regionais em termos de transbordamentos de conhecimento, spillovers tecnológicos e encadeamentos produtivos. Para avaliar o grau de complexificação da estrutura produtiva local foram mensurados os diferenciais regionais dos setores Indústria de Alta e Média Intensidade Tecnológica (IND), os Serviços Produtivos Tradicionais e os Serviços Produtivos Modernos (SPT e SPM). O primeiro reúne classes de atividades da indústria de transformação que possuem alto e médio valor do indicador de intensidade de Pesquisa e Desenvolvimento (P\&D), de acordo com a classificação da OCDE (Hatzichronoglou, 1997). Compreende a parcela das atividades industriais mais complexas - em relação à conectividade e interação dos agentes -, inovadoras, e que possuem maior potencial gerador de efeitos de encadeamentos, para trás e para frente, na economia local.

Os dois últimos setores dessa dimensão, Serviços Produtivos Tradicionais e Serviços Produtivos Modernos, conjuntamente, definem a oferta dos serviços produtivos que possuem relação de interdependência com a indústria. Essa escolha se justifica dada a profunda relação entre urbanização, complexificação do segmento de serviços e progresso tecnológico. As características do capital de concentração e acumulação ocasionam a aglomeração das atividades econômicas, expressas nos grandes centros urbanos, justamente pela baixa transportabilidade dos serviços. Determinadas localidades tornam-se mais atraentes para a alocação das atividades produtivas na medida em que fornecem uma maior diversidade e complexidade de serviços a custos mais baixos, além de permitirem elevada interação entre os agentes econômicos. A conformação de um setor terciário diversificado e complexo é causa e efeito do processo de diversificação industrial, uma vez que ambas as esferas produtivas são necessárias à reprodução eficiente do capital e ao consequente aumento potencial da taxa de lucro (Lemos, 1988).

O setor Serviços Produtivos Tradicionais compreende as atividades de serviços associadas diretamente à indústria. Já o setor Serviços Produtivos Modernos compreende atividades diversas, como tecnologia da informação, atividades financeiras, auditoria, pesquisa e desenvolvimento cientí- 
fico, marketing e consultoria em gestão ambiental. Tais atividades exigem certo grau de concentração urbana e consequente aglomeração relativa das atividades econômicas para serem ofertadas.

\section{Quadro 1 Descrição dos setores contidos na dimensão Complexificação Produtiva}

\begin{tabular}{l|l}
\hline Sigla & Descrição \\
\hline IND & Indústria de Transformação de Médio e Alto Grau Tecnológico* \\
\hline SPT & Serviços Produtivos Tradicionais*** \\
\hline SPM & Serviços Produtivos Modernos ${ }^{* *}$ \\
\hline
\end{tabular}

Fonte: Elaboração própria a partir da Classificação Nacional de Atividades Econômicas, versões 1.0 e 2.0. Nota: * O setor foi adaptado a partir da classificação de Hatzichronoglou (1997) e Freitas e Simões (2012). ${ }^{* *}$ O setor relacionado foi adaptado de Lima (2013). *** Os setores relacionados foram adaptados de Simões (2007). ${ }^{* * * *}$ A explanação detalhada das atividades que compõem cada setor encontra-se em Nahas (2014).

Para cada um dos três setores, considerando os 853 municípios mineiros, foram produzidos quatro indicadores setoriais: a) Quociente Locacional (OL); b) Indicador de Diversidade Setorial (IDS); c) Participação Relativa (PR); e d) Hirschman Herfindal Modificado (HH). ${ }^{10}$

O Quociente Locacional revela os setores regionais que apresentam potencialidades para exportação e aqueles com inclinação para o mercado interno. Considera-se que a economia local é especializada no setor i, caso o valor do QL seja superior à unidade. O OL pode ser considerado variável proxy para especialização produtiva, fonte de externalidades MAR.

O Indicador de Diversidade Setorial reflete não a concentração, mas a diversidade setorial de uma região. Considera-se que o setor s é diversificado na região quanto maior o valor do IDS em relação à região de referência. A diversificação produtiva expressa pelo IDS pode ser indício de externalidades Jacobs.

Apesar da clara adequação desses dois indicadores ao escopo desse artigo, o OL e o IDS são apropriados para regiões de porte médio, ao passo que para pequenas regiões e com estrutura produtiva pouco diversificada, como é o caso da maioria dos municípios mineiros, ambos tendem a sobrevalorizar o peso de determinado setor.

10 Esses indicadores são amplamente retratados na literatura, por essa razão não serão formalmente desenvolvidos. Sobre isso, ver Haddad (1989), Combes (2000), Simões (2005) e Crocco et al. (2006). As fórmulas dos indicadores regionais setoriais estão detalhadas no Anexо 2 . 
Para mitigar essas distorções, foram incluídos os indicadores Participação Relativa (PR) e Hirschman Herfindal Modificado (HH). O primeiro busca identificar a real relevância de determinado setor na estrutura econômica local, e o segundo procura captar o peso do setor selecionado da economia municipal na economia estadual. Ambos, juntamente com o QL, formam o índice de Concentração (IC), cujo objetivo é identificar aglomerações produtivas locais (Crocco et al, 2006). Para sumarizar os indicadores setoriais foi utilizada a Análise de Componentes Principais (ACP). ${ }^{11}$ A seleção do número de componentes principais utilizados se baseou em três critérios: a) priorização dos componentes relacionados aos maiores autovetores e autovalores obtidos; b) variância acumulada, maior ou igual a $75 \%$; e c) elevada representatividade de todos os indicadores setoriais utilizados.

Foram selecionados dois componentes principais para sumarizar a dimensão Complexificação da Capacidade Produtiva. A análise das suas contribuições possibilita identificar indicadores representativos dos diferenciais regionais. $O$ primeiro componente principal pode ser caracterizado como Índice de Concentração Produtiva (c1), pois resume os indicadores setoriais Participação Relativa e Hirschman Herfindal Modificado que se associam à real relevância do setor local, representando principalmente spillovers tecnológicos, oriundos da especialização produtiva, e em menor grau transbordamentos de conhecimento - relacionados à especialização e diversificação produtiva. Já o segundo componente principal se refere ao índice de Especialização e Diversificação (c2), pois se resume aos indicadores Quociente Locacional e Indicador de Diversidade Setorial. Assim, representa fortemente os transbordamentos de conhecimento, originários tanto da especialização quanto da diversificação produtiva. Cada um dos componentes principais foi utilizado como variável resposta de um modelo empírico.

A construção dos indicadores representativos da dimensão Complexificação Produtiva, portanto, foi sumarizada, na equação 1 .

$$
A C P\left(Q L_{i, k} ; I D S_{i, k} ; H H_{i, k} ; P R_{i, k}\right) \Rightarrow c 1 C P_{i} \text { e } c 2 C P_{i}
$$

em que: $A C P$ é aplicação da técnica Análise de Componentes Principais sobre os indicadores setoriais da dimensão Complexificação Produtiva;

11 Metodologia amplamente descrita na literatura recente e formalmente apresentada em Mingoti (2005). 
$Q L_{i, k} ; I D S_{i, k} ; H H_{i, k} ; P R_{i, k}=$ indicadores setoriais para o município $i$ e setor $k$;

$c 1 C P_{i} ; c 2 C P_{i}=$ valor de cada componente principal da dimensão Complexificação Produtiva para o município $i$.

O processo foi sumarizado na Figura 3, a seguir:

Figura 3 Sumário da abordagem empírica para construção das variáveis relacionadas à dimensão Complexificação da Capacidade Produtiva da estrutura produtiva dos municípios de alta intensidade mineral, Minas Gerais - 2000 e 2010

\section{Complexificação Produtiva}

para cada um dos 3 setores, foram produzidos quatro indicadores setoriais:

a) Quociente Locacional proxy MAR

b) Indicador de Diversidade Setorial (Diversificação)

\section{knowledge \\ spillovers \\ Diferenciais Regionais \\ especialização e diversificação}

MODELO II

$Y_{i t}=c 2 C P_{i t}$

c) Participação Telativa (MAR)

d) Hirschman Herfindal Modificado (MAR) spillovers Diferenciais Regionais tecnológicos aglomeração e concentração

\section{MODELO I}

$Y_{i t}=C 1 C P_{i t}$

$$
A C P\left(Q L_{i t k} ; I D S_{i t k} ; H H_{y t k} ; P T_{i t k}\right) \Rightarrow C 1 C P_{i t} \text { e } c 2 C P_{i t}
$$

Fonte: Elaboração própria.

Desse modo, o termo $c_{g} C P_{i}$, pode se explicado como:

$c_{1} C P_{i t}$ variável resposta é o índice de Concentração Produtiva para o município $i$

$c_{2} C P_{i t}$ variável resposta é o índice de Especialização e Diversificação para o município $i$;

Desenvolvimento humano e variáveis associadas

Conforme descreve a literatura sobre o tema, a aglomeração espacial das atividades produtivas pode decorrer de spillovers de capital humano (Hen- 
derson, 1995; Glaeser et al, 2002). A variável Habilidade Local (HAL) foi inserida no modelo com o intuito de controlar tais efeitos.

$$
H A L_{i}=\frac{\operatorname{grad}_{i}}{e m p_{i}}
$$

em que: $\mathrm{grad}_{i}=$ número de trabalhadores graduados no município $i$; e emp = emprego no município $i$.

O fenômeno boom and bust confere peculiaridades ao processo de desenvolvimento humano das regiões mineradoras. É sabido que durante o boom há tendência de crescimento populacional, de renda e emprego. O reverso é observado durante o bust. Essa dinâmica pode influenciar a atratividade local e, consequentemente, os diferenciais regionais setoriais da economia municipal. Faz-se necessária, então, a inclusão de outras variáveis de desenvolvimento humano.

De maneira geral, essas regiões apresentam PIB e PIB per capita superiores ao entorno não minerador. Por outro lado, os efeitos dessa atividade sobre a qualidade de vida, desigualdade e pobreza local são ambíguos (Furtado; Urias, 2013; Borges, 2011; Enriquez, 2008). O conceito de desenvolvimento humano utilizado neste trabalho restringe-se àquele pertinente à renda, qualidade de vida e educação, conforme ilustra o Quadro 2.

Quadro 2 Indicadores da dimensão Desenvolvimento Humano

\begin{tabular}{l|r}
\hline Sigla & Denominação \\
\hline IDH & Índice de Desenvolvimento Humano \\
\hline GINI & Índice de Gini \\
\hline PPOB & Percentual de pobres \\
\hline EAE & Expectativa de anos de estudo \\
\hline T_ANF & Taxa de analfabetismo \\
\hline HAL & Habilidade local \\
\hline PIBpc & PIB per capita municipal \\
\hline RTPpc & Renda do trabalho principal per capita* \\
\hline RNDpc & Renda per capita municipal \\
\hline
\end{tabular}

Fonte: Elaboração própria a partir de dados do IBGE, Censos Demográficos 2000 e 2010 e Atlas do Desenvolvimento Humano, Programa das Nações Unidas para o Desenvolvimento (PNUD), 2003 e 2013.

Nota: * Nesse indicador o termo per capita se relaciona aos ocupados na semana de referência de coleta de dados dos Censos Demográficos 2000 e 2010. 
Foram selecionados três componentes principais para sumarizar os efeitos do desenvolvimento humano sobre a dinâmica produtiva municipal, de acordo com os critérios já explicitados. O componente Desenvolvimento Humano Amplo (DHA) consiste em um índice multiespectral que compara variáveis que contribuem positivamente para o desenvolvimento, como o índice de Desenvolvimento Humano, renda per capita e Habilidade Local, com indicadores que o restringe, tais como: proporção de pobres e taxa de analfabetismo. $\mathrm{O}$ índice de Desenvolvimento Humano, Desigualdade e Renda (DRH) resume-se a um indicador de desigualdade e renda. Por último, tem-se o índice de Anos de Estudo e Riqueza, ANR, que equivale a um indicador de anos de estudo e riqueza.

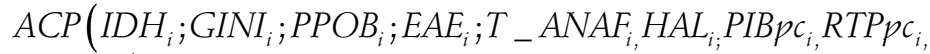

$$
\begin{aligned}
& \left.R D N P c_{i}\right) \Rightarrow D H A_{i}, D R H_{i} e A N R_{i}
\end{aligned}
$$

em que: $A C P$ é aplicação da técnica Análise de Componentes Principais sobre os indicadores de desenvolvimento humano;

$I D H_{i} ;$ GINI $_{i} ; P_{P P O B_{i}} ; E_{\text {EAE }} ; T_{-} A N A F_{i} ; H A L_{i} ;$ PIBPc $_{i} ;$ RTPPC $_{i}=$ indicadores calculados para o município $i ; D H A_{i}, D R H_{i}$ e $A N R_{i}=$ valor de cada componente principal de desenvolvimento humano para o município $i$.

Assim, o termo $D H_{i}$ pode ser expresso como:

$$
D H_{i}=\left\{D H A_{i} ; D R H_{i} ; A N R_{i}\right\}
$$

\section{Atributos regionais e variáveis associadas}

Para North (1990), governos fortes são capazes de reduzir os custos de produção por intermédio dos custos de transação, favorecendo os efeitos da renda advinda da mineração sobre a economia local. Hirschman destaca os "efeitos de cadeia fiscal", isto é, direcionamento da renda proveniente de tributos da base exportadora primária para investimentos produtivos estratégicos, como possíveis catalisadores do desenvolvimento regional.

Os investimentos públicos municipais per capita (INV) compõem o vetor de variáveis explicativas. Conforme descrito por Alexandrino e Simões (2007), em regiões com baixa densidade populacional ou atividade econômica pouco relevante, pode haver sérias distorções de indicadores das 
contas públicas. Na tentativa de mitigá-las foi aplicado um fator de ponderação habilitando a variável INV a expressar simultaneamente intensidade dos investimentos per capita e riqueza municipal.

$$
I N V_{i}=\frac{I N V_{i}}{P I B_{i}}\left\lceil 1-e^{-\left(\frac{-\ln (0,05)}{P I B m g} P I B_{i}\right)}\right\rceil
$$

em que: $I N V_{i}=$ investimentos públicos municipais per capita no município $i$ a preços correntes de 2010; $P I B_{i, t}=P I B$ municipal a preços correntes de 2010 do município $i$ PIB $_{m g}=$ PIB de Minas Gerais a preços correntes de 2010 .

O tamanho da economia ajuda a explicar se as características locais, independentemente dos fatores setoriais, influenciam o crescimento do emprego ao longo do tempo. Assim, é relevante captar diferenças regionais entre os municípios analisados (Combes, 2000; Freitas; Simões, 2012). O indicador de densidade do emprego local (TECL), também incorporado ao vetor de variáveis de controle do modelo, resume-se ao total do emprego dividido pela área municipal, o que reflete o tamanho da economia local. Assim, o termo $A R_{i}$ pode ser expresso como:

$$
A R_{i}=\left\{I N V_{i} ; T E C L_{i}\right\}
$$

\section{Intensidade mineral e variáveis relacionadas}

Com o objetivo de captar o efeito da intensidade mineral sobre a dinâmica produtiva municipal, foram incluídas duas variáveis nas estimações econométricas. A primeira é uma dummy que assume valor igual a 1 apenas para os 22 municípios que integram o grupo Fortemente Minerador (FTM). Tal variável busca captar o efeito da atividade extrativa mineral intensiva sobre o aprofundamento da complexificação produtiva municipal. A segunda representa um termo de interação entre a dummy para o grupo de municípios Fortemente Minerador e a distância, em km, da capital Belo Horizonte (FTMd). A inclusão dessa segunda variável busca explicar se a distância da capital do estado é um fator favorável ou não ao aprofundamento da complexificação produtiva municipal para os 22 municípios pertencentes ao grupo Fortemente Minerador. 
Assim, o conjunto das variáveis de interesse $I M_{i}$ pode ser descrito como:

$$
I M_{i}=\left\{F T M_{i} ; F T M d_{i}\right\}
$$

\subsection{Estratégia de seleção dos modelos empíricos}

A estratégia adotada aqui foi baseada em Golgher (2016) e tem início com a estimação de modelos não espacias de regressão para dados cross-section, seguido pela estimação para dados agrupados na forma empilhada, e dados em painel, seguindo os preceitos tradicionais da econometria não espacial, tal como descreve Wooldridge (2002). O modelo de dados em painel com efeito fixo foi selecionado como o melhor modelo não espacial, pois não houve evidência empírica para aceitar a hipFótese nula de ausência de correlação das variáveis explicativas com o termo de erro.

Para a amostra utilizada neste artigo, no entanto, mesmo o modelo de painel efeito fixo pode apresentar coeficientes ineficientes ou até mesmo inconsistentes, pois assume que as unidades de cross-section são independentes entre si. Assim, foi necessário adaptar o modelo estrutural de dados em painel para a possível presença de dependência espacial entre as unidades de cross-section.

A decisão sobre a introdução de termos de transbordamento espacial no modelo de efeitos fixos se baseou na verificação empírica da autocorrelação espacial dos resíduos por meio do teste I de Moran sobre os resíduos das unidades cross-section ano a ano, conforme descreve Almeida (2012), que constatou a presença de erros autocorrelacionados espacialmente.

A modelagem espacial se inicia com a estimação, em paralelo, do Modelo de Defasagem Espacial (SAR), do Modelo Regressivo Cruzado (SLX) e do Modelo de Erro Auto Regressivo (SEM), para efeitos fixos. Em seguida foram estimados o Modelo de Durbin Espacial (SDM) e do Modelo de Durbin Espacial do Erro (SDEM), para efeitos fixos, amplamente descritos em Almeida (2012).

Ao final das estimações dos modelos espaciais descritos anteriormente, com o propósito de selecionar a modelagem mais adequada, os seguintes critérios foram adotados:

a) Não há significância estatística do componente espacial dos modelos SAR, SLX ou SEM: o modelo e seu correspondente Durbin são descartados; 
b) Não há significância do SDM: os modelos SDM e SAR são eliminados. O SDEM apresenta ambos os coeficientes espaciais significativos: é escolhido;

c) Todos os coeficientes espaciais significativos: escolher o SDM.

A preferência pelo modelo SDM se justifica não só pela sua capacidade de gerar estimativas não viesadas mesmo quando o processo gerador real de dados seja distinto. Para o fenômeno aqui estudado, não só as características de transbordamento local, tais como desenvolvimento humano, tamanho da economia local e gastos públicos municipais dos vizinhos, afetam a diversificação econômica local, mas também a estrutura produtiva dos vizinhos em relação ao aprimoramento do da complexificação produtiva municipal influencia a dinâmica da econômica municipal por meio dos efeitos de transbordamento global. Desse modo, a autocorrelação espacial no modelo SDM implica que o valor das variáveis resposta e explicativas no município i tende a estar associado ao valor dessas variáveis nos municípios vizinhos j. Assim, o modelo espacial estimado é apresentado na Figura 4, a seguir:

Figura 4 llustração do Modelo Empírico Espacial Estimado para capturar os efeitos da indústria extrativa mineral sobre a complexificação produtiva dos municípios com alta intensidade mineral - Minas Gerais, 2000 e 2010

$$
\operatorname{cov}\left(\sum_{j=1}^{N} w_{i j} y_{i t}, \varepsilon_{i t}\right) \neq 0 \quad \operatorname{cov}\left(\sum_{j=1}^{N} w_{i j} y_{i t}, c_{i}\right) \neq 0 \quad \begin{aligned}
& \operatorname{cov}\left(c_{i} c_{j}\right)=0, \operatorname{caso} \mathrm{i} \neq \mathrm{j} ; \\
& \operatorname{cov}\left(c_{i}, \varepsilon_{j t}\right)=0
\end{aligned}
$$$$
\operatorname{cov}\left(x_{i t,} c_{i}\right) \neq 0 \text {; }
$$

autocorrelação espacial da variável resposta

(spillovers globais)

\section{efeitos fixos}

$$
y_{i t}=\rho \sum_{j=1}^{N} w_{i j} y_{i t}+x_{i t} \beta+\sum_{j=1}^{N} w_{i j} X_{i j t} Y+c_{i}+\varepsilon_{i t}
$$

autocorrelação espacial da variável resposta

(spillovers globais)

$$
\operatorname{cov}\left(\sum_{j=1}^{N} w_{i j} x_{i j t}, c_{i}\right) \neq 0
$$

Fonte: Elaboração própria. 
A matriz de Contiguidade, ${ }^{12}$ baseada na proximidade geográfica, foi utilizada para determinar o arranjo das interações espaciais. Assim, duas regiões são vizinhas se elas partilham uma fronteira física comum. ${ }^{13}$

\section{Resultados empíricos}

No ano de 2000, os municípios de alta intensidade mineral apresentaram não especialização, não diversificação e não concentração produtiva nos setores analisados. Os valores médios dos indicadores setoriais para esse grupo de municípios foram superiores à média estadual, retratando que seus sistemas econômicos são complexos em relação aos municípios mineiros. Em outras palavras, na média, há tanto em termos absolutos quanto em termos relativos mais empregos nos setores estudados do que na economia dos municípios mineiros.

O valor diminuto da média do índice de Diversidade Setorial (IDS) dos municípios fortemente mineradores, em relação à média de Minas Gerais, associa-se à escala industrial superior à média estadual, conforme captado pelos indicadores de Participação Relativa (PR). Percebe-se, a partir dos dados da Tabela 1, que os municípios fortemente mineradores diferenciaram-se significativamente em relação à média estadual principalmente em termos do setor Indústria de Transformação de Médio e Alto Grau Tecnológico e, secundariamente, em termos do setor Serviços Produtivos Tradicionais.

No ano de 2010, o padrão produtivo dos municípios de alta intensidade mineral ainda se caracterizava por não especialização, não diversificação e ausência de escala industrial relevante nos setores estudados. Os valores médios dos indicadores setoriais eram superiores à média de Minas Gerais. No entanto, nota-se a variação negativa da ordem de $25 \%$ do indica-

12 Os modelos espaciais também foram estimados utilizando as matrizes de peso espacial dos cinco vizinhos mais próximos e Torre. Porém, houve diferença estatística irrelevante em relação aos coeficientes estimados.

13 Ressalta-se que apesar do uso extensivo de econometria espacial presente neste artigo, o modelo empírico não lida com potencial endogeneidade entre os regressores e a variável resposta. Esse fato pode gerar inconsistência ou enviesamento dos resultados encontrados. Contudo, os resultados encontrados estão de acordo com os relatos empíricos de ocorrência do fenômeno boom and bust mineral para economias com baixa intensidade tecnológica, amplamente relatados na literatura sobre o tema. Portanto, entende-se que a potencial endogeneidade que pode existir nos modelos estimados não compromete os principais resultados apresentados. 
dor OL do grupo dos municípios de alta intensidade mineral, para o setor Indústria de Transformação de Médio e Alto Grau Tecnológico. De acordo com o indicador QL, dos 22 membros desse agrupamento, 15 sofreram redução de especialização produtiva em atividades relacionadas ao setor industrial estudado. A especialização produtiva em atividades relacionadas aos serviços produtivos, sejam eles tradicionais ou modernos, manteve-se estável para o grupo de municípios com alta intensidade mineral. A especialização/não especialização em atividades relacionadas ao setor Serviços Produtivos Modernos manteve-se estável para esse grupo de municípios.

Tabela 1 Indicadores setoriais pertencentes à dimensão Complexificação da Capacidade Produtiva para Belo Horizonte, grupo Fortemente Minerador e Minas Gerais, anos 2000 e 2010

\begin{tabular}{|c|c|c|c|c|c|c|c|c|c|c|c|c|}
\hline Localidade & $\begin{array}{l}\text { ql_ } \\
\text { IND }\end{array}$ & $\begin{array}{l}\text { ql_ } \\
\text { SPT }\end{array}$ & $\begin{array}{l}\text { ql_- } \\
\text { SPM }\end{array}$ & $\begin{array}{l}\text { ids } \\
\text { IND }\end{array}$ & $\begin{array}{c}\text { ids_ } \\
\text { SPT }\end{array}$ & $\begin{array}{l}\text { ids_ } \\
\text { SPM }\end{array}$ & $\begin{array}{l}\text { pr_ } \\
\text { IND }\end{array}$ & $\begin{array}{l}\mathrm{pr}_{-} \\
\text {SPT }\end{array}$ & $\begin{array}{l}\mathrm{pr}_{-} \\
\text {SPM }\end{array}$ & $\begin{array}{l}\text { hh_ } \\
\text { IND }\end{array}$ & $\begin{array}{l}\text { hh_ } \\
\text { SPT }\end{array}$ & $\begin{array}{c}\text { hh_ } \\
\text { SPM }\end{array}$ \\
\hline \multicolumn{13}{|l|}{2000} \\
\hline Belo Horizonte & 1,21 & 2,14 & 2,56 & 1,05 & 1,04 & 1,05 & 0,16 & 0,29 & 0,35 & 0,03 & 0,15 & 0,21 \\
\hline Média FTM & 1,35 & 0,85 & 0,64 & 0,99 & 1,01 & 1,03 & 0,00 & 0,00 & 0,00 & 0,00 & 0,00 & 0,00 \\
\hline Média MG & 0,48 & 0,40 & 0,40 & 1,03 & 1,02 & 1,05 & 0,00 & 0,00 & 0,00 & 0,00 & 0,00 & 0,00 \\
\hline Média + dp MG & 1,46 & 0,86 & 0,73 & 1,07 & 1,03 & 1,07 & 0,01 & 0,01 & 0,01 & 0,00 & 0,01 & 0,01 \\
\hline Média - dp MG & $-0,50$ & $-0,06$ & 0,08 & 0,99 & 1,01 & 1,02 & $-0,01$ & $-0,01$ & $-0,01$ & 0,00 & $-0,01$ & $-0,01$ \\
\hline \multicolumn{13}{|l|}{2010} \\
\hline Belo Horizonte & 1,21 & 2,24 & 2,52 & 1,02 & 1,04 & 1,06 & 0,16 & 0,30 & 0,34 & 0,03 & 0,17 & 0,20 \\
\hline Média FTM & 1,02 & 0,81 & 0,64 & 1,00 & 1,01 & 1,03 & 0,00 & 0,00 & 0,00 & 0,00 & 0,00 & 0,00 \\
\hline Média MG & 0,49 & 0,41 & 0,39 & 1,02 & 1,03 & 1,05 & 0,00 & 0,00 & 0,00 & 0,00 & 0,00 & 0,00 \\
\hline Média + dp MG & 1,54 & 0,80 & 0,67 & 1,05 & 1,05 & 1,08 & 0,01 & 0,01 & 0,01 & 0,00 & 0,01 & 0,01 \\
\hline Média - dp MG & $-0,57$ & 0,02 & 0,10 & 0,99 & 1,01 & 1,03 & $-0,01$ & $-0,01$ & $-0,01$ & 0,00 & $-0,01$ & $-0,01$ \\
\hline
\end{tabular}

Fonte: Elaboração própria a partir de dados do Censo Demográfico, 2000 e 2010.

A Tabela 2 apresenta os resultados da Análise de Componentes Principais utilizando como atributos tais indicadores setoriais de economia regional. O componente c1 se relaciona ao índice de Concentração Produtiva, e o componente c2 refere-se ao índice de Especialização e Diversificação. Em conjunto, os dois índices construídos contemplam tanto especificidades locais, transbordamentos de conhecimento, quanto concentração produtiva, spillovers tecnológicos. Assim, a utilização desses índices em separado, enquanto variável resposta dos modelos empíricos, objetiva captar os efeitos 
líquidos sobre a complexificação produtiva dos municípios de alta intensidade mineral durante a bonança mineral.

Tabela 2 Coeficientes dos componentes principais para a amostra dos municípios mineiros, setores Indústria de Alta e Média Intensidade Tecnológica (IND), Serviços Produtivos Tradicionais (SPT) e Serviços Produtivos Modernos (SPM), dimensão Complexificação da Capacidade Produtiva (2000 e 2010)

\begin{tabular}{|c|c|c|c|c|c|c|}
\hline \multirow[b]{2}{*}{ Indicador } & \multicolumn{3}{|r|}{2000} & \multicolumn{3}{|r|}{2010} \\
\hline & cl & c2 & $\begin{array}{l}\text { Singula- } \\
\text { ridade }\end{array}$ & cl & c2 & $\begin{array}{r}\text { Singula- } \\
\text { ridade }\end{array}$ \\
\hline qI_IND & 0,126 & 0,370 & 0,452 & 0,124 & 0,364 & 0,482 \\
\hline ql_SPT & 0,176 & 0,378 & 0,425 & 0,207 & 0,348 & 0,436 \\
\hline ql_SPM & 0,216 & 0,321 & 0,455 & 0,244 & 0,321 & 0,400 \\
\hline ids_IND & $-0,092$ & $-0,385$ & 0,481 & $-0,091$ & $-0,378$ & 0,507 \\
\hline ids_SPT & $-0,060$ & $-0,427$ & 0,457 & $-0,102$ & $-0,408$ & 0,478 \\
\hline ids_SPM & $-0,099$ & $-0,395$ & 0,501 & $-0,118$ & $-0,408$ & 0,459 \\
\hline pr_IND & 0,408 & $-0,045$ & 0,109 & 0,398 & $-0,044$ & 0,163 \\
\hline pr_SPT & 0,416 & $-0,147$ & 0,021 & 0,414 & $-0,169$ & 0,022 \\
\hline pr_SPM & 0,407 & $-0,169$ & 0,036 & 0,406 & $-0,189$ & 0,033 \\
\hline hh_IND & 0,352 & 0,069 & 0,345 & 0,322 & 0,071 & 0,403 \\
\hline hh_SPT & 0,406 & $-0,177$ & 0,034 & 0,399 & $-0,207$ & 0,045 \\
\hline hh_SPM & 0,389 & $-0,205$ & 0,077 & 0,384 & $-0,232$ & 0,077 \\
\hline
\end{tabular}

Fonte: Elaboração própria a partir de dados do IBGE, Censos Demográficos 2000 e 2010.

Validada a consistência da sumarização dos diferenciais regionais por meio da técnica de Análise de Componentes Principais, resta saber se eles podem ser explicados pela intensidade mineral municipal. As Tabelas 3 e 4 mostram os resultados das estimações espaciais dos modelos sumários dos diferenciais regionais na dimensão Complexificação da Capacidade Produtiva.

Os resultados contidos na Tabela 3 referem-se aos diferenciais regionais de concentração produtiva dos setores estudados. $\bigcirc$ modelo espacial selecionado foi o SDM, indicando que tanto os efeitos transbordamentos locais quanto os globais são importantes para o entendimento da dinâmica produtiva dos municípios mineiros entre os anos 2000 e 2010.

Tanto os índices associados à dimensão Desenvolvimento Humanos (DHA, DRH e ANR) como os gastos municipais com Investimentos (INV) possuíram efeitos positivos sobre a concentração produtiva nos setores 
analisados. Esses resultados indicam que as características populacionais são importantes fatores de atração para atividades produtivas complexas, mas também que economias que investem relativamente mais ou que foram beneficiadas de maneira mais expressiva por programas de investimento público em geral, e que ao mesmo tempo têm expressividade estadual, em termos de PIB, apresentaram incrementos na absorção de atividades dos setores analisados.

Tabela 3 Resultados das estimações espaciais dos modelos com a variável resposta Índice de Concentração Produtiva, amostra dos municípios de Minas Gerais, anos 2000 e 2010

\begin{tabular}{|c|c|c|c|c|c|}
\hline Variáveis & SAR & SEM & SLX & SDM & SDEM \\
\hline DHA & $\begin{array}{r}* * 0,078 \\
(0,003)\end{array}$ & $\begin{array}{l}0,014 \\
(0,19)\end{array}$ & $\begin{array}{r}* * 0,083 \\
(0,033)\end{array}$ & $\begin{array}{r}* * * 0,083 \\
(0,000)\end{array}$ & $\begin{array}{r}* * * 0,084 \\
(0,001)\end{array}$ \\
\hline DRH & $\begin{array}{r}* * * 0,059 \\
(0,001)\end{array}$ & $\begin{array}{r}* * * 0,040 \\
(0,001)\end{array}$ & $\begin{array}{r}* * * 0,082 \\
(0,001)\end{array}$ & $\begin{array}{r}* * * 0,079 \\
(0,000)\end{array}$ & $\begin{array}{r}* * * 0,078 \\
(0,000)\end{array}$ \\
\hline ANR & $\begin{array}{r}* * * 0,046 \\
(0,007)\end{array}$ & $\begin{array}{r}* * * 0,028 \\
(0,006)\end{array}$ & $\begin{array}{r}{ }^{* *} 0,057 \\
(0,019)\end{array}$ & $\begin{array}{r}* * * 0,055 \\
(0,001)\end{array}$ & $\begin{array}{r}* * * 0,054 \\
(0,001)\end{array}$ \\
\hline INV & $\begin{array}{r}* * * 0,326 \\
(0,000)\end{array}$ & $\begin{array}{r}* * * 1,175 \\
(0,000)\end{array}$ & $\begin{array}{r}* * * 0,315 \\
(0,000)\end{array}$ & $\begin{array}{r}* * * 0,319 \\
(0,000)\end{array}$ & $\begin{array}{r}* * * 0,314 \\
(0,000)\end{array}$ \\
\hline TECL & $\begin{array}{r}* * *-0,004 \\
(0,000)\end{array}$ & $\begin{array}{r}* * *-0,003 \\
(0,000)\end{array}$ & $\begin{array}{r}* * *-0,001 \\
(0,000)\end{array}$ & $\begin{array}{r}* * *-0,001 \\
(0,000)\end{array}$ & $\begin{array}{r}* * *-0,001 \\
(0,000)\end{array}$ \\
\hline FTM & $\begin{array}{r}* * * 0,919 \\
(0,000)\end{array}$ & $\begin{array}{r}* * *-0,916 \\
(0,000)\end{array}$ & $\begin{array}{r}* * * 0,693 \\
(0,010)\end{array}$ & $\begin{array}{r}* * * 0,756 \\
(0,000)\end{array}$ & $\begin{array}{r}* * *-0,732 \\
(0,000)\end{array}$ \\
\hline FTMd & $\begin{array}{r}* * * 0,002 \\
(0,004)\end{array}$ & $\begin{array}{r}* * 0,003 \\
(0,002)\end{array}$ & $\begin{array}{l}* 0,002 \\
(0,089)\end{array}$ & $\begin{array}{r}* * * 0,002 \\
(0,007)\end{array}$ & $\begin{array}{r}* * * 0,002 \\
(0,010)\end{array}$ \\
\hline$\lambda$ & - & $\begin{array}{r}* * * 0,236 \\
(0,000) \\
\end{array}$ & - & - & $\begin{array}{r}* * * 0,188 \\
(0,000) \\
\end{array}$ \\
\hline$\rho$ & $\begin{array}{l}* * 0,158 \\
(0,041)\end{array}$ & - & - & $\begin{array}{r}* * * 0,132 \\
(0,000)\end{array}$ & - \\
\hline I.DHA & - & - & $\begin{array}{r}* * * 0,191 \\
(0,005) \\
\end{array}$ & $\begin{array}{r}* * * 0,139 \\
(0,003) \\
\end{array}$ & $\begin{array}{r}* * * 0,152 \\
(0,003) \\
\end{array}$ \\
\hline I.DRH & - & - & $\begin{array}{r}{ }^{*} 0,101 \\
(0,056)\end{array}$ & $\begin{array}{r}* * 0,083 \\
(0,023)\end{array}$ & $\begin{array}{l}{ }^{*} 0,102 \\
(0,010)\end{array}$ \\
\hline I.ANR & - & - & $\begin{array}{r}0,005 \\
(0,916)\end{array}$ & $\begin{array}{r}0,005 \\
(0,891)\end{array}$ & $\begin{array}{r}0,024 \\
(0,505)\end{array}$ \\
\hline
\end{tabular}


Tabela 3 (continuação)

\begin{tabular}{|c|c|c|c|c|c|}
\hline Variáveis & SAR & SEM & SLX & SDM & SDEM \\
\hline I.INV & - & - & $\begin{array}{l}-0,003 \\
(0,909)\end{array}$ & $\begin{array}{r}* * *-0,076 \\
(0,001)\end{array}$ & $\begin{array}{r}-0,012 \\
(0,580)\end{array}$ \\
\hline I.TECL & - & - & $\begin{array}{r}* * * 0,006 \\
(0,006)\end{array}$ & $\begin{array}{r}* * * 0,004 \\
(0,002)\end{array}$ & $\begin{array}{r}* * *-0,005 \\
(0,001)\end{array}$ \\
\hline I.FTM & - & - & $\begin{array}{r}{ }^{* *} 0,551 \\
(0,031)\end{array}$ & $\begin{array}{r}{ }^{* *} 0,799 \\
(0,022)\end{array}$ & $\begin{array}{r}{ }^{* *} 0,706 \\
(0,037)\end{array}$ \\
\hline I.FTMd & - & - & $\begin{array}{r}* *-0,0071 \\
(0,016)\end{array}$ & $\begin{array}{r}* * *-0,007 \\
(0,000)\end{array}$ & $\begin{array}{r}* * *-0,007 \\
(0,001)\end{array}$ \\
\hline
\end{tabular}

Fonte: Elaboração própria a partir de dados do IBGE, Censos Demográficos 2000 e 2010 e Atlas do Desenvolvimento Humano, PNUD, 2003 e 2013, Tesouro Nacional, Finanças do Brasil - Dados Contábeis dos Municípios (Finbra), 2000 e 2010.

Nota: *** significativo a $1 \%,{ }^{* *}$ a $5 \%, e *$ a $10 \%$.

A utilização da modelagem de dados em painel permite captar a dinâmica da mudança temporal em determinado fenômeno. Tal efeito pode ser exemplificado pelo sinal negativo e significativo das variáveis Tamanho da Economia Local (TECL) e Fortemente Minerador (FTM). No caso do tamanho da economia local, esse resultado demonstra que economias maiores e mais adensadas que já possuíam elevado padrão de concentração produtiva em 2000 obtiveram, ao longo da década, ganhos relativos inferiores às de pequeno e de médio porte nos setores analisados. Já o sinal negativo da variável de interesse dummy FTM pode indicar que, ao longo do tempo, os municípios de alta intensidade mineral sofreram redução dos diferenciais regionais de concentração produtiva nos setores analisados. Em consulta aos dados originais, foi possível verificar que esse movimento não significa perdas absolutas, mas sim relativas. Ou seja, ao longo do tempo, os municípios contidos no grupo Fortemente Minerador (FTM) possuíam valores médios dos indicadores: Participação Relativa (PR) e Hirschamn-Herfindal modificado (HH) superiores à média mineira em 2000 e 2010. No entanto, durante a década de 2000, outros municípios mineiros conseguiram elevar os valores desses indicadores, enquanto o valor médio do grupo FTM manteve-se aproximadamente constante.

Esse fato foi vivenciado de forma mais acentuada nos municípios fortemente mineradores mais próximos de Belo Horizonte, conforme captado pelo coeficiente positivo e significativo da variável Distância do Município 
Fortemente Minerador de Belo Horizonte (FTMd). Nesse caso o fácil acesso a atividades complexas inibiu o desenvolvimento de empreendimentos locais, ou os empregos gerados localmente, vinculados a atividades complexas, utilizaram o estoque de capital humano altamente qualificado da população residente em Belo Horizonte, em relação ao entorno. Em contraposição à sua representante não espacial, os coeficientes positivos das defasagens espaciais das variáveis de interesse indicam que os municípios vizinhos a municípios mineradores obtiveram incrementos dos diferenciais de concentração produtiva ao longo do tempo. Mais ainda, quanto mais próximos esses municípios vizinhos estão de Belo Horizonte maior foi o incremento obtido. Assim, resta concluir que a atratividade local de atividades contidas nos setores analisados está comprometida quando há, no âmbito municipal, demanda por uma gama variada de serviços relacionados à mineração.

Esses resultados indicam duas possibilidades: a) durante a bonança mineral novos empreendimentos relacionados à dimensão Complexificação da Capacidade Produtiva preferiram alocar-se em municípios não pertencentes ao grupo Fortemente Minerador (dummy FTM =0) ou; b) houve migração de negócios de municípios de alta intensidade mineral para o seu entorno não minerador. Qualquer que seja a hipótese verdadeira, o fato é que durante a bonança mineral houve perda de atratividade dos municípios de alta intensidade mineral para o seu entorno. Portanto, houve vazamento de empregos ou pelo menos de novas oportunidades associadas aos setores analisados dos municípios fortemente mineradores (dummy FTM =1) para seus vizinhos.

A defasagem espacial da variável resposta possuía efeito positivo sobre o incremento de concentração produtiva. Assim, ao longo do tempo, a concentração produtiva de atividades complexas nos municípios vizinhos contribuiu favoravelmente à própria escala industrial municipal. Em outros termos, há a tendência de formação de clusters geográficos de municípios em relação à concentração produtiva nos setores analisados.

O nível de desenvolvimento humano dos vizinhos também apresentou efeito positivo sobre a concentração produtiva, indicando que regiões abundantes em capital humano, qualidade de vida e renda também são aquelas que detiveram, ao longo do tempo, maiores diferenciais de escala industrial nos setores contidos na dimensão Complexificação Produtiva.

A defasagem espacial dos investimentos per capita municipais ponderados possuía coeficiente negativo e significativo. Como essa variável rela- 
ciona-se com os investimentos intencionais da administração pública, esse resultado pode retratar um comportamento free rider municipal. Ou seja, quando um dado município, geralmente o de maior porte regional, decide investir na provisão de um equipamento público, como a modernização de um vetor rodoviário, a população residente dos municípios vizinhos também usufrui desse bem público, diminuindo o incentivo ao próprio município vizinho em prover um equipamento semelhante. Já o sinal negativo da defasagem do tamanho da economia local pode ser explicado pela tendência de aglomeração das atividades produtivas em um dado centro urbano diversificado. Isto é, caso o município j vizinho ao i seja um município de grande porte os novos negócios tendem a ser atraídos para o $\mathrm{j}$, em detrimento do i.

Tabela 4 Resultados das estimações espaciais dos modelos com a variável resposta Índice de Especialização e Diversificação, amostra dos municípios de Minas Gerais, anos 2000 e 2010

\begin{tabular}{|c|c|c|c|c|c|}
\hline \multirow{2}{*}{ Variáveis } & SAR & SEM & SLX & SDM & SDEM \\
\hline & Coeficiente & Coeficiente & Coeficiente & Coeficiente & Coeficiente \\
\hline DHA & $\begin{array}{r}0,032 \\
(0,300)\end{array}$ & $\begin{array}{r}0,033 \\
(0,319)\end{array}$ & $\begin{array}{r}0,035 \\
(0,433)\end{array}$ & $\begin{array}{r}0,037 \\
(0,200)\end{array}$ & $\begin{array}{r}0,037 \\
(0,190)\end{array}$ \\
\hline DRH & $\begin{array}{l}{ }^{*} 0,037 \\
(0,089)\end{array}$ & $\begin{array}{l}{ }^{*} 0,036 \\
(0,074)\end{array}$ & $\begin{array}{r}0,031 \\
(0,330) \\
\end{array}$ & $\begin{array}{l}{ }^{*} 0,030 \\
(0,061)\end{array}$ & $\begin{array}{l}{ }^{* *} 0,031 \\
(0,044)\end{array}$ \\
\hline ANR & $\begin{array}{r}0,009 \\
(0,660)\end{array}$ & $\begin{array}{r}0,003 \\
(0,945)\end{array}$ & $\begin{array}{r}0,005 \\
(0,894)\end{array}$ & $\begin{array}{l}-0,002 \\
(0,893)\end{array}$ & $\begin{array}{r}0,003 \\
(0,801)\end{array}$ \\
\hline INV & $\begin{array}{l}{ }^{*} 0,004 \\
(0,061)\end{array}$ & $\begin{array}{l}{ }^{*} 0,003 \\
(0,067)\end{array}$ & $\begin{array}{r}{ }^{*} 0,010 \\
(0,046)\end{array}$ & $\begin{array}{l}{ }^{*} 0,009 \\
(0,044)\end{array}$ & $\begin{array}{l}{ }^{*} 0,009 \\
(0,042)\end{array}$ \\
\hline TECL & $\begin{array}{r}* *-0,001 \\
(0,044)\end{array}$ & $\begin{array}{r}* *-0,001 \\
(0,034)\end{array}$ & $\begin{array}{r}*-0,002 \\
(0,086)\end{array}$ & $\begin{array}{r}*-0,002 \\
(0,080)\end{array}$ & $\begin{array}{r}* *-0,002 \\
(0,037)\end{array}$ \\
\hline FTM & $\begin{array}{r}* *-0.507 \\
(0,013)\end{array}$ & $\begin{array}{r}* * *-0,606 \\
(0,005)\end{array}$ & $\begin{array}{r}* *-0,996 \\
(0,013)\end{array}$ & $\begin{array}{r}* * *-1,013 \\
(0,000)\end{array}$ & $\begin{array}{r}* * * 0,960 \\
(0,000)\end{array}$ \\
\hline FTMd & $\begin{array}{r}0,001 \\
(0,171)\end{array}$ & $\begin{array}{l}{ }^{*} 0,002 \\
(0,087)\end{array}$ & $\begin{array}{l}{ }^{*} 0,003 \\
(0,068)\end{array}$ & $\begin{array}{r}* * * 0,003 \\
(0,006)\end{array}$ & $\begin{array}{r}* * * 0,003 \\
(0,012)\end{array}$ \\
\hline$\Lambda$ & - & $\begin{array}{r}* * * 0,163 \\
(0,000)\end{array}$ & - & - & $\begin{array}{r}* * * 0,153 \\
(0,000)\end{array}$ \\
\hline$P$ & $\begin{array}{r}* * * 0,155 \\
(0,000)\end{array}$ & - & - & $\begin{array}{r}* * * 0,150 \\
(0,000)\end{array}$ & - \\
\hline
\end{tabular}


Tabela 4 (continuação)

\begin{tabular}{|c|c|c|c|c|c|}
\hline \multirow{2}{*}{ Variáveis } & SAR & SEM & SLX & SDM & SDEM \\
\hline & Coeficiente & Coeficiente & Coeficiente & Coeficiente & Coeficiente \\
\hline \multirow{2}{*}{ I.DHA } & - & - & 0,005 & 0,006 & 0,017 \\
\hline & & & $(0,734)$ & $(0,717)$ & $(0,617)$ \\
\hline \multirow{2}{*}{ I.DRH } & - & - & $-0,009$ & $-0,007$ & 0,003 \\
\hline & & & $(0,854)$ & $(0,770)$ & $(0,567)$ \\
\hline \multirow{2}{*}{ I.ANR } & - & - & ${ }^{* *} 0,165$ & $* * * 0,162$ & *** 0,181 \\
\hline & & & $(0,011)$ & $(0,000)$ & $(0,003)$ \\
\hline \multirow{2}{*}{ I.INV } & - & - & 0,036 & 0,035 & 0,034 \\
\hline & & & $(0,199)$ & $(0,156)$ & $(0,095)$ \\
\hline \multirow{2}{*}{ I.TECL } & - & & 0,000 & $-0,001$ & $-0,001$ \\
\hline & & - & $(0,406)$ & $(0,352)$ & $(0,347)$ \\
\hline \multirow{2}{*}{ I.FTM } & - & - & $* * * 1,373$ & $* * * 1,365$ & $* * * 1,299$ \\
\hline & & & $(0,010)$ & $(0,000)$ & $(0,037)$ \\
\hline \multirow{2}{*}{ I.FTMd } & - & - & $* *-0,006$ & $* * *-0,007$ & $* * *-0,007$ \\
\hline & & & $(0,012)$ & $(0,000)$ & $(0,001)$ \\
\hline
\end{tabular}

Fonte: Elaboração própria a partir de dados do IBGE, Censos Demográficos 2000 e 2010 e Atlas do Desenvolvimento Humano, PNUD, 2003 e 2013, Tesouro Nacional, Finanças do Brasil - Dados Contábeis dos Municípios (Finbra), 2000 e 2010.

Nota: ${ }^{* *}$ significativo a $1 \%,{ }^{* *}$ a $5 \%$ e * a $10 \%$.

A Tabela 4 exibe os resultados dos modelos que possuem como variável resposta o componente principal c2, índice de Especialização Diversificação, composto principalmente dos indicadores OL e IDS. Pela menor variabilidade do IDS e no sentido oposto da especialização e diversificação produtiva para a maioria dos municípios mineiros, o sinal positivo dos coeficientes das variáveis explicativas deve ser associado ao aprofundamento da especialização e da não diversificação produtiva. Além de absorver percentual diminuto da variância amostral em relação ao índice de Concentração produtiva o índice de Especialização e Diversificação é carregado dos indicadores QL e IDS, sujeitos a distorções para localidades pequenas e grandes. Assim, esse modelo dispõe de menor poder explicativo e relativa perda de significância.

Da mesma forma, o modelo espacial selecionado foi o SDM para efeitos fixos. Apenas um índice associado à dimensão Desenvolvimento Humano foi significativo a $10 \%$ de probabilidade, indicando que desenvolvimento humano e o incremento de especialização produtiva caminharam juntos, 
durante a década de 2000, para os municípios mineiros. Além disso, municípios cuja administração pública local efetuou maiores investimentos per capita municipais ponderados também foram aqueles que obtiveram diferenciais regionais de especialização nos setores analisados.

No período, as economias menores foram aquelas que obtiveram maiores incrementos de especialização produtiva, revelando tendência suave à redução das disparidades regionais em termos da complexificação da estrutura produtiva local.

O sinal negativo do coeficiente da variável de interesse dummy Fortemente Minerador (FTM) revela redução relativa e absoluta dos diferenciais regionais de especialização nos setores analisados. Em consulta aos dados originais, foi possível constatar que 15, 11 e 12 municípios sofreram redução dos indicadores OL dos setores Indústria de Alta e Média Intensidade Tecnológica, Serviços Produtivos Tradicionais e Serviços Produtivos Modernos, respectivamente, entre os anos 2000 e 2010. O valor médio desses indicadores para o grupo de municípios de alta intensidade mineral (dummy FTM = 1) também diminuiu, enquanto o valor médio para amostra dos municípios mineiros apenas diminuiu para o setor Serviços Produtivos Modernos. Essa transição foi mais intensa para os municípios mineradores mais próximos a Belo Horizonte, conforme ilustrado pelo coeficiente positivo do termo de interação Distância do Município Fortemente Minerador de Belo Horizonte (FTMd).

O coeficiente significativo e positivo da defasagem espacial l. FTM indica que os municípios vizinhos aos elementos do grupo de municípios de alta intensidade mineral (dummy FTM = 1) alcançaram incrementos de especialização produtiva nos setores analisados. Quanto menor a distância do município vizinho a Belo Horizonte, maior a magnitude do movimento em questão, conforme ilustra o coeficiente da variável l.FTMd.

A defasagem espacial da variável resposta apresentou coeficiente significativo e positivo, indicando que há tendência de formação de clusters de municípios especializados nas atividades contidas na dimensão Complexificação da Capacidade Produtiva. O nível de desenvolvimento humano dos vizinhos exerceu efeito positivo sobre o próprio diferencial de especialização produtiva municipal. Assim, regiões abundantes em capital humano, qualidade de vida e renda também são aquelas que detiveram, ao longo do tempo, maiores diferenciais regionais na dimensão Complexificação Produtiva. 


\section{Considerações finais}

Este artigo teve por objetivo analisar os efeitos líquidos da mineração sobre a complexificação produtiva dos maiores municípios mineradores de Minas Gerais. Para isso, utilizaram-se indicadores de economia regional e urbana e um modelo de painel espacial.

Os principais resultados indicaram que, ao longo da década de 2000, houve redução relativa e absoluta dos diferenciais regionais possuídos pelos municípios com alta intensidade mineral, especialmente aqueles mais próximos a Belo Horizonte. Tal fenômeno foi observado tanto com relação aos diferenciais regionais de concentração produtiva, spillovers tecnológicos quanto em relação aos diferenciais regionais de especialização e diversificação, transbordamentos de conhecimento, conferindo consistência aos resultados empíricos obtidos e evidenciando o empobrecimento produtivo ocorrido nesses municípios durante o período do superciclo mineral.

Essa dinâmica econômica vivenciada pelos municípios de alta intensidade mineral de Minas Gerais é, de certo modo, surpreendente, uma vez que a maioria dessas localidades gozam de localização geográfica privilegiada - Região Metropolitana ou Colar Metropolitano de Belo Horizonte - o que lhes confere elevada atratividade de atividades industriais complexas e de serviços produtivos associados.

Pela existência de outros fatores não contidos no escopo temporal deste artigo, os municípios com alta intensidade mineral possuíam diferenciais regionais na dimensão Complexificação Produtiva no ano 2000. Portanto, com relação a essas atividades, os municípios mineradores exibiam estreita relação com a dinâmica produtiva de Belo Horizonte em 2000, de forma a se beneficiar de sua localização estratégica e a absorver, principalmente, atividades contidas nos setores Indústria de Alta e Média Intensidade Tecnológica e Serviços Produtivos Tradicionais.

Durante o período em análise, que compreende a maior parte do superciclo mineral, esses municípios passaram pela intensificação da sua especialização produtiva mineral. Essa maior atratividade da atividade extrativa mineral pode ter ocasionado menor atratividade de outras atividades, por exemplo, aquelas contidas nos setores analisados e que não são essenciais à reprodução do processo produtivo extrativo mineral. No período estudado houve clara redução dos indicadores de especialização produtiva e de participação relativa, bem como diminuição relativa dos indicadores 
de concentração produtiva. Apenas os indicadores de diversificação sofreram variações positivas consistentes, ao longo do tempo, indicando em alguns casos pluralização da economia local, e em outros o esvaziamento produtivo setorial.

A contradição central desse processo produtivo situa-se na dissociação produtiva entre o setor terciário e o desenvolvimento da indústria, no caso o setor Extrativo Mineral que, ao desenvolver-se, expulsa ou pelo menos restringe o aprofundamento das relações de atividades complementares, principalmente os Serviços Produtivos Tradicionais. Os resultados das estimações espaciais, no entanto, possibilitaram a compreensão desse fenômeno ao evidenciar que o desenvolvimento da mineração durante o superciclo mineral gerou fortes oportunidades de complexificação da estrutura produtiva para o município de Belo Horizonte, que centraliza os Serviços Produtivos Modernos e, secundariamente, os Serviços Produtivos Tradicionais, mas também para o entorno não minerador da capital do estado que, por não abrigarem empreendimentos minerais tão expressivos, possuem terras mais baratas e abundantes disponíveis para o estabelecimento de negócios correlatos, mas livres da rigidez locacional da mineração em si.

Desse modo, a transferência de tecnologia, conhecimento e renda das firmas minerais para a população residente e firmas locais dos territórios minerários foi limitada durante o período do superciclo mineral. Não só o hiato tecnológico, mas outros condicionantes como a própria atratividade da mineração, o formato hub de operação das plantas minerais e a proximidade geográfica com Belo Horizonte limitaram a complexificação da estrutura produtiva dos municípios de alta intensidade mineral.

A partir da perspectiva da equidade intergeracional, teoria do bem-estar, percebe-se ainda outro fator de atenção para os efeitos locais da mineração em Minas Gerais. Os bens minerais existentes no subsolo dos municípios de alta intensidade mineral que foram extraídos entre os anos 2000 e 2010 não representaram incrementos de poupança ou consumo per capita para as gerações futuras, residentes nessas localidades. Isso ocorre tanto em função do vazamento de renda, dos empregos e das possibilidades de negócios quanto em função da ausência de uma política pública para gerenciar a parte da renda mineral absorvida pelo município de alta intensidade mineral.

Do ponto de vista de políticas públicas, o bom uso da renda mineral é apontado como alternativa para que as localidades mineradoras reduzam 
sua dependência da atividade. No entanto, as limitações sobre a utilização da cota parte da CFEM não foram suficientes para garantir a diversificação produtiva nos municípios analisados. Esse fato corrobora a necessidade de planejar e executar iniciativas de diversificação econômica em âmbito regional. Para tal, a criação de um fundo para desenvolvimento de territórios minerários é uma alternativa promissora no âmbito das políticas públicas. A futura disponibilização da base de dados do Censo Demográfico de 2020 (IBGE) irá possibilitar ampliar o número de períodos de tempo na análise de dados e a introdução do fator dinâmico ao estudo dos dados em painel espacial e melhorar a modelagem empírica em relação à endogeneidade potencial. A ampliação do período estudado também permitirá capturar a completitude dos efeitos do superciclo mineral sobre a estrutura produtiva dos municípios de alta intensidade mineral de Minas Gerais, do choque positivo de demanda por commodities minerais, permitindo trabalhos empíricos herméticos e capazes de captar o fenômeno boom and bust.

\section{Referências}

ARROW, K. J. The Economic Implications of Learning by Doing. Review of Economic Studies, 29(3): 155-173, 1962.

ARTHUR, W. B. Competing Technologies and Lock-In by Historical Small Events: The Dynamics of Allocation under Increasing Returns. International Institute for Applied Analysis Paper 93-82]. Laxenburg, Austria. Center for Economic Policy Research [Paper 43]. Stanford. 1983.

AUTY, R.; WARHURST, A. Sustainable Development in Mineral Exporting Economies. Resources Policy, 25, 1993.

BORGES, M. S. A. Indústria extrativa e dinâmica de pobreza em Minas Gerais. Dissertação (Mestrado) - Programa de Pós-Graduação em Economia (PIMES), Universidade Federal de Pernambuco, 2011.

BRASIL, Ministério de Minas e Energia. Plano Nacional da Mineração 2030. Brasília, 2010.

COMBES, P. P. Economic Structure and Local Growth: France, 1984-1993. Journal of Urban Economics, 47: 329-355, 2000.

COSTA, A. V.; VIANA C. K. R. De sertão inóspito às Minas do ouro. Memória do Judiciário Mineiro, 201, 2012.

CROCCO, M. A. et al. Metodologia de identificação de aglomerações produtivas locais. Nova Economia, 16(2), 2006.

DAVIS, G. A. Learning to Love the Dutch Disease: Evidence from the Mineral Economies. Word Development. Canada: Elsevier 23, 1995. 
DAVIS, G. A. The Minerals Sector, Sectoral Analysis, and Economic Development. Resources Policy, 24(4): 217-228, 1998.

DAVIS, G. A.; TILTON, J. E. Should Developing Countries Renounce Mining? A Perspective on the Debate. [s.n], 2002.

DOMAR, E. Capital Expansion, Rate of Growth and Employment. Econometrica, Journal of the Econometric Society, 14(2), 1946.

ENRIQUEZ, M. A. R. S. Mineração: maldição ou dádiva? Os dilemas do desenvolvimento sustentável a partir de uma base mineira. São Paulo: Signus, 2008.

FERNANDES, C. L. L.; ROCHA, R. B. Os setores-chave da economia de Minas Gerais: uma análise a partir das matrizes de insumo-produto de 1996 e 2005. In: XI SEMINÁRIO DE ECONOMIA MINEIRA, Diamantina/MG, 2010. Anais...

FERRANTI, D. et al. Natural Resources to the Knowledge Economy. IBRD: Washington DC, 2002.

FOCHEZATTO, A. Desenvolvimento regional: recomendações para um novo paradigma produtivo. GRANDO, M. Z. et al. (Org.). Três décadas de economia gaúcha: o ambiente regional. Porto Alegre: FEE, 2010.

FREITAS, H. E.; SIMÕES, R. Intensidade tecnológica e diferenciais regionais de produtividade: evidência de economias externas nas microrregiões brasileiras, 2000-2010. Artigo de divulgação científica. Confederação Nacional da Indústria (CNI), 2012.

FREUBENBURG, W.R.; GRAMILING, R. Linked to What? Economic Linkages in an Extractive. Society and Natural Resource, n. 11, 1998.

FURTADO, J.; URIAS, E. Recursos naturais e desenvolvimento: estudos sobre o potencial dinamizador da mineração na economia brasileira. Edição dos autores/IBRAM. 2013. GALINARI, R. Retornos crescentes urbano-industriais e spillovers espaciais: evidências a partir da taxa salarial no estado de São Paulo. Dissertação (Mestrado em Economia) - Universidade Federal de Minas Gerais, Belo Horizonte, 2006.

GLAESER, L. E. et al. Growht in Cities. Journal of Political Economy, 100(6), 1992.

GOLGHER, A. B. Introdução à Econometria Espacial. Curitiba: Editora CRV, 2016.

GRILICHES, Z. The Search for R\&D Spillovers. Scandinavian Journal of Economics, 94: 29$-47,1992$.

HADDAD, P. R. (Org.). Economia regional, teorias e métodos de análise. Fortaleza: BNB/ETENE, 1989.

HARROD, R. An Essay in Dynamic Theory. The Economic Journal, 49, 1938.

HATZICHRONOGLOU, T. Revision of the High-Technology Sector and Product Classification. [Working Paper n. 1997/02[. OECD Science, Technology and Industry Working Papers, 1997.

HENDERSON, J. V; KUNCORO, A.; TURNER, M. Industrial Development in Cities. Journal of Political Economy, 103(5): 1067-1090, 1995.

HIRSCHMAN, A. O. The Strategy of Economic Development. New Haven: Yale University Press, 1958.

HIRSCHMAN, A. O. O desenvolvimento por efeitos em cadeia: uma abordagem generalizada. Estudos CEBRAP, 18, 1976. 
IGLESIAS, R. Análise dos grandes projetos de investimento no Espírito Santo. Espírito Santo: Instituições desenvolvimento e inclusão social. Instituto Jones dos Santos Neves, 2010. v. 1.

JACOBS, J. The Economy of Cities. New York, 1969.

KOKKO, A. Technology, Market Characteristics, and Spillovers. Journal of Development Economics, 43, 1994.

LAZZERETTI, L. Cultural and Creative Industries. In: LAZZERETTI, L. Creative Industries and Innovation Europe. Regional Studies Association, USA, 2013.

Lewis, A. W. Economic Development with Unlimited Supply of Labor. The Manchester School, 22: 139-191, 1954.

LIMA, A. C. C.; SIMÕES, R. F. Desenvolvimento regional e fluxo migratório no Brasil: uma análise para o período 1980-2010. Dissertação (Mestrado) - CEDEPLAR/UFMG, 2013.

LIMA, A. C. C.; SIMÕES, R. F. Teorias do desenvolvimento regional e suas implicações de política econômica no pós-guerra: o caso do Brasil. Revista de Desenvolvimento Econômico, 2: 5-19, 2010.

LORENTZEN, A. Leisure, Culture and Experience Economy as a Creative Strategy in the Periphery. In: LAZZERETTI, L. Creative Industries and Innovation Europe. Regional Studies Association, USA, 2013.

MINGOTI, S. A. Análise de dados através de métodos de estatística multivariada: uma abordagem aplicada. Belo Horizonte: Editora UFMG, 2005.

MARSHALL, A. Location Theory and Regional Economic Growth. Journal of Political Economy, 63, 1955.

MARSHALL, A. Institucions, Institutional Change and Economic Performance. Cambridge University Press, 1990.

MARSHALL, A. Principles of Economics. London: Macmillan, 1890.

NAHAS, M. Mineração e dinâmica produtiva: efeitos da indústria extrativa mineral sobre a estrutura produtiva dos municípios mineradores de Minas Gerais. Dissertação (Mestrado) - Universidade Federal de Minas Gerais, Belo Horizonte, 2014.

PEGG, S. Mining and Porverty Reduction: Transforming Rhetoric into Reality. Journal of Cleaner Production, 14, 2006.

RADETZKI, M. Economic Growth and Environment. In: LOW, P. International Trade and the Environment, World Bank. Discussion Papers 159, 1992.

RODRIGUEZ-CLAIRE, A. Multinationals, Linkage and Economic Development. American Economic Review, 86, 1996.

ROMER, P. Increasing Returns and Long-Run Growth. Journal of Political Economy, 94(5), 1986.

SHAFER, D. M. Winners and Losers: How Sectors Shape the Developmental Prospects of States. Ithaca: Cornell University Press, 1994.

SIMÕES, R. Métodos de análise regional e urbana: diagnóstico aplicado ao planejamento. Belo Horizonte: CEDEPLAR/UFMG, 2005. (Texto para Discussão).

SIMONATO, T. C. Projeção dos impactos regionais do desastre de Mariana - MG. Belo Horizonte: CEDEPLAR/UFMG, 2016. 
VIANA, M. B. Avaliando minas: índice de sustentabilidade da mineração. 2012. Tese (Doutorado) - CDS/UnB, Brasília, 2012.

WARHURST, A Mining \& Sustainable Development. Mining \& Energy Research Network [Paper 177, 1999].

WHITEMORE, A. The Emperor's New Clothes: Sustainable Mining? Journal of Cleaner Production, 14, 2006.

\section{Sobre os autores}

Mariana Medeiros Nahas-m.nahas0901@gmail.com

Doutoranda em Economia, CEDEPLAR da Universidade Federal de Minas Gerais, Belo Horizonte, Minas Gerais, Brasil. ORCID: https://orcid.org/0000-0001-7647-9044.

Rodrigo Ferreira Simões - limoes@cedeplar.ufmg.br

CEDEPLAR da Universidade Federal de Minas Gerais, Belo Horizonte, Minas Gerais, Brasil.

ORCID: https://orcid.org/0000-0001-5242-4153.

AndréBraz Golgher-agolgher@cedeplar.ufmg.br

CEDEPLAR da Universidade Federal de Minas Gerais, Belo Horizonte, Minas Gerais, Brasil.

ORCID: https://orcid.org/0000-0001-5884-225X.

Luiz Carlos de Santana Ribeiro - ribeiro.luiz84@gmail.com

Universidade Federal de Sergipe, Aracajú, Sergipe, Brasil.

ORCID: https://orcid.org/0000-0001-6374-3811.

\section{Sobre 0 artigo}

Recebido em 31 de janeiro de 2016. Aprovado em 16 de novembro de 2017. 


\section{APÊNDICE A}

Tabela A1 Maiores municípios mineradores de Minas Gerais para o ano de 2010

\begin{tabular}{l|l|r|r|r}
\hline Posição & Município & $\begin{array}{r}\text { Valor da opera- } \\
\text { ção mineral* }\end{array}$ & $\begin{array}{r}\text { Arrecadação } \\
\text { da CFEM** }\end{array}$ & $\begin{array}{r}\text { Receitas } \\
\text { correntes }\end{array}$ \\
\hline 1 & Nova Lima & 4.603 & 101 & 315 \\
\hline 2 & Itabira & 4.085 & 90 & 307 \\
\hline 3 & Mariana & 3.553 & 78 & 172 \\
\hline 4 & São Gonçalo do Rio Abaixo & 3.063 & 67 & 103 \\
\hline 5 & Congonhas & 2.272 & 50 & 200 \\
\hline 6 & Brumadinho & 1.996 & 44 & 110 \\
\hline 7 & Itabirito & 1.805 & 41 & 116 \\
\hline 8 & Ouro Preto & 1.245 & 27 & 190 \\
\hline 9 & Paracatu & 1.120 & 25 & 130 \\
\hline 10 & Barão de Cocais & 927 & 20 & 62 \\
\hline 11 & Itatiaiuçu & 901 & 20 & 38 \\
\hline 12 & Sabará & 692 & 15 & 137 \\
\hline 13 & Santa Bárbara & 449 & 10 & 44 \\
\hline 14 & Mateus Leme & 362 & 8 & 38 \\
\hline 15 & Catas Altas & 331 & 7 & 21 \\
\hline 16 & Araxá & 331 & 7 & 189 \\
\hline 17 & Rio Piracicaba & 318 & 7 & 26 \\
\hline 18 & Igarapé & 245 & 5 & 42 \\
\hline 19 & Tapira & 236 & 5 & 23 \\
\hline 20 & São Joaquim de Bicas & 175 & 4 & 34 \\
\hline 21 & Vazante & 157 & 3 & 36 \\
\hline 22 & Conceição do Pará & 138 & 3 & 14 \\
\hline
\end{tabular}

Fonte: Elaboração própria a partir de dados do Departamento Nacional de Produção Mineral.

* Nota: Valores em milhões de reais a preços correntes de 2010. ${ }^{* *}$ Nota: A contribuição da mineração para as receitas correntes municipais não se limita a CFEM. A arrecadação de ICMS, de IPTU e outras receitas próprias também estão vinculadas à atividade extrativa mineral. 


\section{APÊNDICE B}

Fórmulas dos indicadores regionais utilizados

$$
\begin{aligned}
& \mathrm{OL}_{\mathrm{ij}}=\frac{\mathrm{E}_{\mathrm{ij}} / \mathrm{E}_{\mathrm{i} .}}{\mathrm{E}_{\mathrm{i}} / \mathrm{E}_{.}} \\
& I D S=\frac{1 / \sum_{\substack{i \neq 1 \\
i^{\prime} \neq 1}}^{\mathrm{i}}\left[\mathrm{E}_{\mathrm{j}, \mathrm{i}^{\prime}} / \mathrm{E}_{\mathrm{j}}-\mathrm{E}_{\mathrm{j}, \mathrm{i}}\right]^{2}}{\left.\mathrm{E}_{\mathrm{i}^{\prime}} / \mathrm{E}-\mathrm{E}_{\mathrm{i}}\right]^{2}} \\
& \operatorname{PR}_{\mathrm{ij}}=\frac{\mathrm{E}_{\mathrm{ij}}}{\mathrm{E}_{\mathrm{i} .}} \\
& \mathrm{HHm}_{\mathrm{i}, \mathrm{j}}=\frac{\mathrm{E}_{\mathrm{i}, \mathrm{j}}}{\mathrm{E}_{\mathrm{i}}}-\frac{\mathrm{E}_{\mathrm{j}}}{\mathrm{E}}
\end{aligned}
$$

onde:

$E_{i j}$ é o número de empregados no setor $i$ do município $j$;

$E_{i}$ é o número de empregados no setor $i$ de Minas Gerais;

$E_{. j}$ é o número de empregados do município $j$ e

E.. é o número de empregados de Minas Gerais. 